\title{
Modification of Grey Cast Iron by Compositions Based on Nano-Disperse Powders of Tungsten and Titanium Carbides
}

\author{
Vladimir A. Poluboyarov ${ }^{a, b}$, Zoya A. Korotaeva ${ }^{a}$, \\ Alexander A. Zhdanok ${ }^{\mathrm{a}}$ and Fedor K. Gorbunov ${ }^{\mathrm{a}, \mathrm{b}}$ \\ ${ }^{a}$ Institute of Solid State Chemistry \\ and Mechanochemistry SB RAS \\ 18 Kutateladze Str., Novosibirsk, 630128, Russia \\ ${ }^{b}$ Novosibirsk State Technical University \\ 20 Karl Marks, Novosibirsk, 630073, Russia
}

Experiments involving modification of cast iron manufactured in China which is similar to Russian grades (SCh-18 - SCh-30) using the compositions based on a mixture of tungsten and titanium carbides were carried out. Nanodispersed carbide powders were obtained by means of self-propagating high-temperature synthesis (SHS) in combination with preliminary mechanical activation (MA). The studied modifying agents were WC:TiC $=70: 30$ with protector metals: chromium (50/50, M1 modifying agent); chromium and copper (25/25/50, modifying agent M2) within the range of concentrations of the ceramic phase - 0.01-0.2\%; the modifying agents were introduced into the casting mold and into foundry ladle. Two designs of casting molds were studied. The use of modifying agents for intra-mold modification may lead to an increase in the tensile strength up to $18.5 \%$, relative corrosion stability in hydrochloric acid up to $58.8 \%$. After modification in ladle, the strength of the samples increased to $25-29 \%$ only after storage for 3.5 months. The results provide evidence that the studies of grey cast iron modification by the agents containing nanodispersed ceramic phases (WC, TiC) should take into account not only the concentrations and composition of modifying agents but also various technological parameters (design, mold volume, method of introduction of the modifying agent etc.).

Keywords: intra-mold modification, grey cast iron, titanium and tungsten carbides, corrosion stability, protector metal, mechanical activation, tensile strength, hardness.

Citation: Poluboyarov V.A., Korotaeva Z.A., Zhdanok A.A., Gorbunov F.K. Modification of grey cast iron by compositions based on nano-disperse powders of tungsten and titanium carbides, J. Sib. Fed. Univ. Eng. technol., 2019, 12(2), $192-202$. DOI: $10.17516 / 1999-494 X-0128$.

(C) Siberian Federal University. All rights reserved

This work is licensed under a Creative Commons Attribution-NonCommercial 4.0 International License (CC BY-NC 4.0).

* Corresponding author E-mail address: a-zhdanok@mail.ru 


\title{
Модифицирование серого чугуна составами \\ на основе нанодисперсных порошков \\ карбидов вольфрама и титана
}

\author{
В.А. Полубояров ${ }^{\mathrm{a}, \boldsymbol{0}}$, З.А. Коротаева ${ }^{\mathrm{a}}$, \\ А.А. Жданок ${ }^{\text {a }}$ Ф.К. Горбунов ${ }^{\mathrm{a}, \boldsymbol{\sigma}}$ \\ ${ }^{a}$ Институт химии твердого тела и механохимии СО РАН \\ Россия, 630128, Новосибирск, ул. Кутателадзе, 18 \\ ${ }^{6}$ Новосибирский государственный технический университет \\ Россия, 630073, Новосибирск, пр. Карла Маркса, 20
}

\begin{abstract}
Проведень эксперименты по модифицированию чугунов китайского производства, аналогичных российским маркам (СЧ-18 - СЧ-30), с использованием составов на основе смеси карбидов вольфрама и титана (нанодисперсные порошки карбидов были получень методом самораспространяющегося высокотемпературного синтеза (CВС) в сочетании с предварительной механической активацией (МА)). Были исследованы модификаторы состава WC:TiC = 70:30 с металлами-протекторами: хромом (50/50, модификатор М1); хромом и медью (25/25/50, модификатор М2) в пределах концентраций керамической фазы-0,01-0,2\%; модификаторы вводили в форму и кови. Были исследованы две конструкиии литейных форм. Применение модификаторов при внутриформенном модифицировании может увеличить предел прочности при растяжении до 18,5\%, относительную коррозионную стойкость в соляной кислоте - до 58,8\%. При модифицировании в ковще прочность образиов увеличилась до 25-29 \% лишь после 3,5 месяцев хранения. Полученные результаты свидетельствуют о том, что при исследовании прочессов модифицирования серого чугуна модификаторами, содержащими нанодисперсные керамические фазы (WC, TiC), необходимо учитывать не только кониентрачии и состав модификаторов, но и различные технологические параметры (конструкиия, объем литейной формы, способ введения модификаторов и другие).
\end{abstract}

Ключевые слова: внутриформенное модифицирование, серый чугун, карбиды титана и вольфрама, коррозионная стойкость, металл-протектор, механическая активация, предел прочности при растяжении, твердость.

\section{Введение}

Увеличение эксплуатационных характеристик (прочности при разрыве, твердости, износостойкости, коррозионной стойкости и в конечном итоге срока службы) чугунов, сталей является актуальной задачей. Качество отливок зависит от многих технологических параметров, которые оказывают влияние на процессы кристаллизации расплава (температура заливки, формовочная смесь, химический состав, объем отливки, перегрев металла при выплавке и др.) [1]. Кроме того, перечисленные технологические факторы оказывают влияние на состав и количество фаз, размер зерна, различные дефекты кристаллической решетки.

В настоящее время большой интерес приобретает использование наноматериалов в металлургии для улучшения качества изделий. Модифицирующие наноразмерные тугоплавкие частицы могут, во-первых, служить центрами зародышеобразования и кристаллизации, тем самым увеличивая их количество, во-вторых, блокировать диффузию соответствующих атомов к зарождающимся и растущим кристаллам, замедляя их рост [2-9]. Экспериментально 
установлено, что чем больше зародышей в единице объема расплава, тем больше кристаллов образуется, тем они мельче и тем выше механические свойства металла $[10,11]$.

По этой причине в сплавах намеренно стараются облегчить формирование зародышей кристаллизации. Вещество, способствующее образованию зародышей, называют модификатором, а саму операцию - модифицированием.

Согласно [12] частицы, находящиеся в объеме металла, оказывают влияние на динамику дислокаций, так как создают препятствия для их движения. Такой материал можно рассматривать как дисперсно-упрочненный композит. Под действием приложенного напряжения источники дислокаций образуют дислокационные петли, окружающие частицы. Число петель дислокаций $\mathrm{n}$ зависит от расстояния между частицами:

$$
\mathrm{n}=\mathrm{l}_{\mathrm{p}} \sigma / \mathrm{G}_{\mathrm{m}}|\mathrm{b} \rightarrow|
$$

где $1_{p}$ - расстояние между частицами; $\sigma$ - приложенное напряжение; $G_{m}$ - модуль сдвига материала матрицы; $\mathrm{b} \rightarrow$ - вектор Бюргерса дислокации. Напряжение сдвига, действующего на частицу, равно:

$$
\tau=l_{p} \sigma^{2} / G_{m}|b \rightarrow|,
$$

а предел текучести материала, упрочненного частицами, равен:

$$
\sigma_{\mathrm{T}}=\left(\mathrm{G}_{\mathrm{p}} \mathrm{G}_{\mathrm{m}}|\mathrm{b} \rightarrow| / \mathrm{l}_{\mathrm{p}} \mathrm{C}\right)^{0,5},
$$

где $\mathrm{G}_{\mathrm{p}}$ - модуль сдвига материала частицы; $\mathrm{C}$ - постоянная, характеризующая тип материала. Причем модуль сдвига материала частицы $\mathrm{G}_{\mathrm{p}}$ должен превосходить модуль сдвига материала матрицы $\mathrm{G}_{\mathrm{m}}$, иначе упрочнения не произойдет. Если частица не смочена материалом, то тогда между материалом и частицей будет пузырь с модулем сдвига, равным нулю, поэтому из формулы (3) видно, что предел текучести равен нулю и, следовательно, материал разупрочняется. Чтобы частицы другой фазы могли изменять свойства материала, они должны смачиваться этим материалом. В противном случае эти частицы выступают в качестве дефектов структуры, ухудшающих свойства материала.

Механохимия может существенно облегчить путь к достижению положительного результата. Обработка в высокоэнергетических активаторах планетарного типа позволяет не только измельчать материал, но и активировать частицы порошков, а дополнительное плакирование частиц дает возможность получать модификаторы, хорошо смачиваемые расплавами [13-16].

Несмотря на большое количество модификаторов, предлагаемых на рынке, проблема получения модификаторов на основе тугоплавких ультрадисперсных частиц, смачиваемых расплавом, равномерно распределенных в металлической матрице, и проблема получения стабильных результатов при модифицировании служат объектом пристального внимания многих исследователей.

Целью настоящей работы является повышение служебных характеристик литых изделий из серого чугуна посредством введения в расплавы структурирующих добавок на основе нанодисперсных карбидов вольфрама и титана, полученных комбинированным методом (самораспространяющимся высокотемпературным синтезом в сочетании с предварительной механической активацией). 


\section{Методика эксперимента}

Эксперименты по модифицированию были проведены с использованием чугунов китайского производства (аналогичных российским маркам СЧ-18 - СЧ-30). Нанодисперсные порошки карбидов вольфрама и титана состава WC:TiC $=70: 30$ были получены методом CBC в сочетании с предварительной механической активацией по методике, описанной в [17].

Так как керамические материалы плохо смачиваются расплавом чугуна, порошки были дополнительно обработаны в активаторе АГО-3 с металлами-протекторами хромом и медью. Были получены модификаторы состава: (WC, TiC)/Cr/Cu : 50/50/0 (модификатор M1) и (WC, $\mathrm{TiC}) / \mathrm{Cr} / \mathrm{Cu}: 25 / 25 / 50$ (модификатор M2). Модификаторы применяли в виде порошков, концентрации модификаторов (керамической фазы) - в пределах 0,01-0,2 \%.

Выплавка чугуна производилась в индукционной печи, емкость тигля 400 кг. Чугун разливали при температуре $1350{ }^{\circ} \mathrm{C}$, при этом индукционная печь была постоянно включена. Модифицирование проводили в форме (масса металла 20-40 кг) и ковше, при этом в ковш заливали количество металла, необходимое для последующей заливки одной или двух форм (предварительно ковш прогрели газом для удаления влаги). Состав материала для изготовления литейных форм - песчано-глинистая смесь (ПГС) и холодно-твердеющая смесь (ХТC).

В ходе экспериментов отливали до десяти образцов: один - без модификатора (на нижний фильтр помещали пустую алюминиевую фольгу), остальные - с различными модификаторами, завернутыми также в алюминиевую фольгу. Были подобраны технологические режимы, при реализации которых не происходило вытекания металла из форм, не было перелива и выплесков чугуна.

Каждую отлитую заготовку (после полного остывания) взвешивали и рассчитывали количество введенного модификатора.

Среднее значение предела прочности при растяжении получали по шести измерениям, что обеспечивало корректность получаемых данных. Для характеристики твердости материалов использовали метод Бринелля. Измерения проводили в различных точках образца (не менее пяти отпечатков) и сравнивали их значения со значениями, полученными при исследовании контрольного образца.

Коррозионную стойкость исследовали по ГОСТ 9.908 - 85 на двух подготовленных образцах чугуна (модифицированном и контрольном). Для измерения относительной коррозионной стойкости образцы должны иметь примерно одинаковый диаметр и высоту, т.е. поверхность, контактирующая с агрессивной средой, должна быть одинаковой. Испытания проводили в $25 \%$-ной соляной кислоте.

Модифицирование серого чугуна.

Исследование влияния различных технологических параметров на служебные характеристики

Исследование влияния концентрации модификатора и способа введения. Для экспериментов использовали модель литейной формы (№ 1), которая представляет собой систему из стояка посредине заготовки длиной до 300 мм (верхний диаметр 150 мм, нижний - 100 мм) и шести цилиндров вокруг стояка (диаметром 30-40 мм). Заливка металла производится в цен- 
тральную часть, откуда металл сифонной заливкой (снизу вверх) поступает в цилиндрические заготовки [13]. Для того чтобы модификатор не всплывал, в форму устанавливали два керамических фильтра, между которыми помещали модификатор. Состав материала для изготовления литейных форм - песчано-глинистая смесь (ПГС). Использовали модификаторы $M 1$ и $M 2$, концентрации керамической фазы модификаторов - в пределах 0,013-0,062 \%.

Химический состав контрольного образца чугуна (без модификатора) дан в табл. 1.

Условия модифицирования (состав, количество модификатора, способ введения) изложены в табл. 2: образец 1 - контрольный без модификатора, образцы 2-4 - с модификатором $M 2$, образец 5 - с модификатором M1. Во второй и третий образцы модификаторы были помещены в стояк формы (между двумя фильтрами), в четвертый и пятый образцы модификаторы ввели в ковш под струю металла (количество металла в ковше такое же, как в форме, - примерно 40 кг).

Свойства образцов чугуна - предел прочности при растяжении, твердость по Бринеллю, а также изменение прочности и твердости относительно контрольного (немодифицированного) образца даны в табл. 3. Увеличение прочности при растяжении составило от 1,1 до 18,5 \% (образцы 2-5), увеличение твердости по Бринеллю составило от 2,8 до 11,3 (образцы 3-5), у образца 2 твердость снизилась на 6,6 \% относительно контрольного образца 1.

Относительная коррозионная стойкость увеличилась от 7,2 до 44,1 \%, причем максимальные значения 37,6 и 44,1 \% получены при модифицировании в ковше (образцы 4 и 5 соответственно).

На рис. 1-3 приведены микрофотографии шлифов образцов чугуна. У всех модифицированных образцов (рис. 2,3 ) наблюдается измельчение графитовых включений по сравнению

Таблица 1. Химический состав чугуна

Table 1. Chemical composition of cast iron

\begin{tabular}{|c|c|c|c|c|c|c|c|c|c|}
\hline Элементы & $\mathrm{C}$ & $\mathrm{Si}$ & $\mathrm{Mn}$ & $\mathrm{P}$ & $\mathrm{S}$ & $\mathrm{Cr}$ & $\mathrm{Ti}$ & $\mathrm{Cu}$ & $\mathrm{W}$ \\
\hline $\begin{array}{c}\text { Массовая доля } \\
\text { элементов, \% }\end{array}$ & 3,27 & 1,92 & 0,68 & 0,056 & 0,014 & - & 0,09 & 0,022 & 0,017 \\
\hline
\end{tabular}

Таблица 2. Условия модифицирования

Table 2. Conditions of modification

\begin{tabular}{|c|c|c|c|c|}
\hline \multirow{2}{*}{ Номер } & \multicolumn{4}{|c|}{ Модификатор } \\
\cline { 2 - 5 } & Название & $\begin{array}{c}\text { Состав } \\
(\mathrm{WC}, \mathrm{TiC}) / \mathrm{Cr} / \mathrm{Cu}, \%\end{array}$ & $\begin{array}{c}\text { Концентрация } \\
\text { керамической фазы, } \%\end{array}$ & Способ введения \\
\hline 1 & - & - & - & - \\
\hline 2 & $M 2$ & $25 / 25 / 50$ & 0,033 & форма \\
\hline 3 & $M 2$ & $25 / 25 / 50$ & 0,013 & форма \\
\hline 4 & $M 2$ & $25 / 25 / 50$ & 0,034 & ковш \\
\hline 5 & $M 1$ & $50 / 50 / 0$ & 0,062 & ковш \\
\hline
\end{tabular}


Таблица 3. Свойства образцов чугуна

Table 3. Properties of cast iron samples

\begin{tabular}{|c|c|c|c|c|c|}
\hline Номер & $\begin{array}{c}\text { Предел прочности } \\
\text { при растяжении, МПа }\end{array}$ & $\begin{array}{c}\text { Твердость, } \\
\text { единиц HBW }\end{array}$ & $\begin{array}{c}\text { Изменение } \\
\text { прочности, \% }\end{array}$ & $\begin{array}{c}\text { Изменение } \\
\text { твердости, \% }\end{array}$ & $\begin{array}{c}\text { Изменение относительной } \\
\text { коррозионной } \\
\text { стойкости, \% }\end{array}$ \\
\hline 1 & 178 & 177 & & & \\
\hline 2 & 211 & 166 & 18,5 & $-6,6$ & 13,7 \\
\hline 3 & 209 & 197 & 17,4 & 11,3 & 7,2 \\
\hline 4 & 190 & 182 & 6,7 & 2,8 & 44,1 \\
\hline 5 & 180 & 194 & 1,1 & 9,6 & 37,6 \\
\hline
\end{tabular}

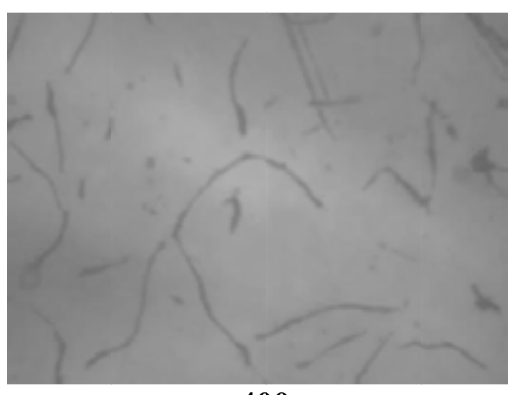

$\times 400$

Рис. 1. Микрофотография немодифицированного образца

Fig. 1. Microphotographs of unmodified sample
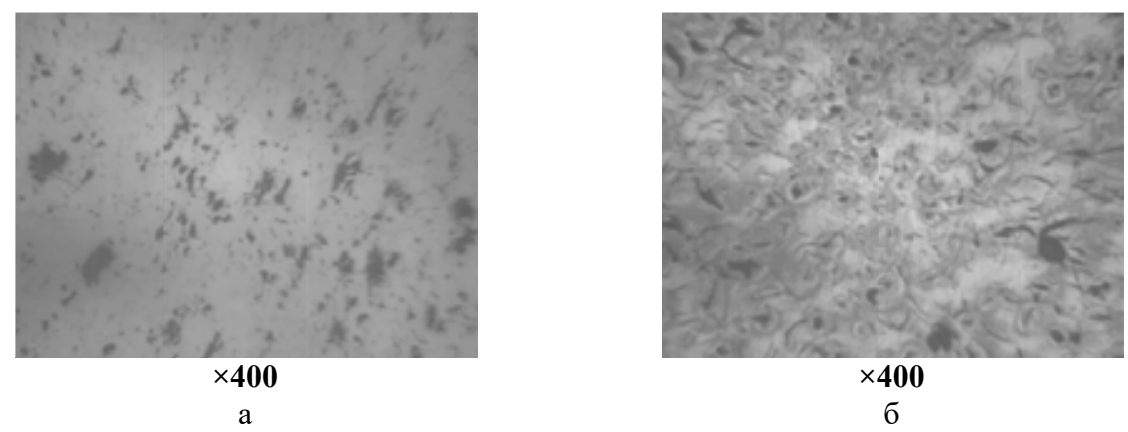

Рис. 2. Микрофотографии образцов, модифицированных в форме: а) образец 2 (WC, TiC - 0,033 \%); б) образец 3 ( $\mathrm{WC}, \mathrm{TiC}-0,013 \%)$

Fig. 2. Microphotographs of samples modified in the form: a) sample 2 (WC, TiC $-0.033 \%$; б) sample 3 (WC, $\mathrm{TiC}-0.013 \%)$

с контрольным образцом 1 (рис. 1). Образцы, модифицированные в форме (рис. 2, образцы 2 и 3) и ковше (рис. 3, образцы 4 и 5), отличаются распределением и формой графитовых включений.

Исследование влияния «естественного старения». После 3,5 месяцев хранения («естественного старения») прочность образцов 2 и 3, модифицированных в форме, уменьшилась 

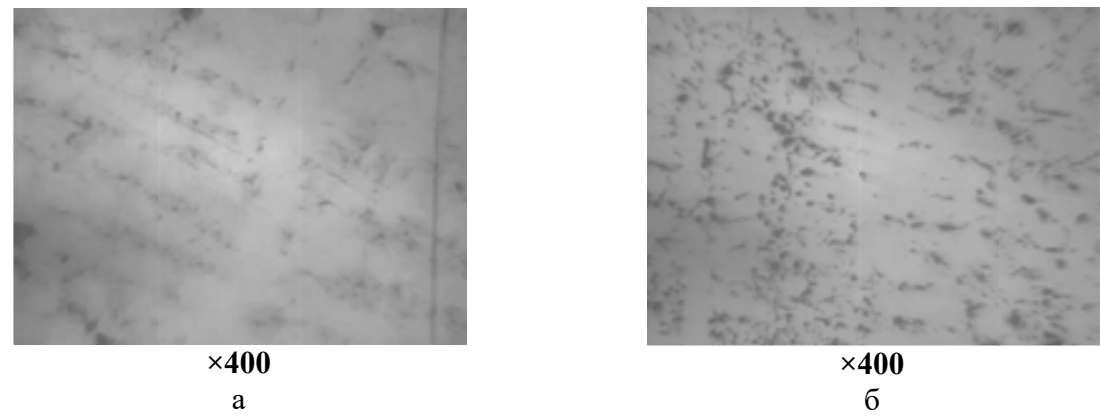

Рис. 3. Микрофотографии образцов, модифицированных в ковше: а) образец 4 (WC, TiC - 0,034 \%); б) образец $5(\mathrm{WC}, \mathrm{TiC}-0,062 \%)$

Fig. 3. Microphotographs of samples modified in the ladle: a) sample 4 (WC, TiC $-0.034 \%$ ); б) sample 5 (WC, $\mathrm{TiC}-0.062 \%)$

Таблица 4. Влияние «естественного старения»

Table 4. Influence of "natural aging"

\begin{tabular}{|c|c|c|c|c|c|}
\hline \multirow{2}{*}{$№$} & $\begin{array}{c}\text { Предел } \\
\text { прочности при } \\
\text { растяжении, МПа }\end{array}$ & $\begin{array}{c}\text { Изменение } \\
\text { прочности } \\
\text { относительно } \\
\text { К, \% }\end{array}$ & $\begin{array}{c}\text { Образцы через 3,5 месяца хранения } \\
\text { прочности при } \\
\text { растяжении, МПа }\end{array}$ & $\begin{array}{c}\text { Изменение } \\
\text { Прочности } \\
\text { относительно } \\
\text { К1, \% }\end{array}$ & $\begin{array}{c}\text { прочности в } \\
\text { результате } \\
\text { «старения», \% }\end{array}$ \\
\hline 1 & 2 & 3 & 4 & 5 & 6 \\
\hline 1 & $178($ К) & & $170($ К1) & & $-4,7$ \\
\hline 2 & 211 & 18,5 & 209 & 22,9 & $-0,9$ \\
\hline 3 & 209 & 17,4 & 205 & 20,6 & $-1,9$ \\
\hline 4 & 190 & 6,7 & 220 & 29,4 & 15,8 \\
\hline 5 & 180 & 1,1 & 213 & 25,3 & 18,3 \\
\hline
\end{tabular}

примерно на 1-2 \%, т.е. практически не изменилась; прочность контрольного образца К1 (после «старения») уменьшилась на 4,7 \% (образец 1) относительно контрольного К (табл. 4, 6-й столбец).

Прочность образцов 4 и 5, модифицированных в ковше (концентрации керамических частиц 0,034 и 0,062 \%), увеличилась на 29,4 и 25,3 \% относительно контрольного (К1) (табл. 4, 5-й столбец); изменение (увеличение) прочности в результате «старения» для этих образцов составило 15,8 и 18,3\% соответственно (табл. 4, 6-й столбец).

Влияние концентрации модификатора на коррозионную стойкость. Влияние концентрации модификатора на коррозионную стойкость исследовали на двух марках чугуна, аналогичных российским маркам СЧ-20 и СЧ-30. Использовали модель литейной формы (№ 2) в виде «стакана», масса чугуна 19 кг. Состав материала для изготовления литейных форм - ПГС и ХТС. Использовали модификатор $M 2$, концентрации керамической фазы модификатора - в пределах 0,01-0,2 \%.

В пределах концентраций керамической фазы 0,025-0,2 \% относительная коррозионная стойкость в 0,1 М соляной кислоте увеличилась с 22,7 до 58,8 \% (образцы 2-7, табл. 5); при кон- 
Таблица 5. Влияние концентрации модификатора на относительную коррозионную стойкость

Table 5. Influence of modifier concentration on relative corrosion resistance

\begin{tabular}{|c|c|c|c|c|c|}
\hline № & Марка чугуна & Модификатор & $\begin{array}{c}\text { Конц. керамической } \\
\text { фазы, \% }\end{array}$ & $\begin{array}{c}\text { Изменение относительной } \\
\text { корр. стойкости, \% }\end{array}$ & $\begin{array}{c}\text { Формовочная } \\
\text { смесь }\end{array}$ \\
\hline 1 & СЧ-20 & \multirow{7}{*}{$M 2$} & 0,01 & $-6,2$ & ПГС \\
\hline 2 & СЧ-20 & & 0,025 & 26,8 & ПГС \\
\hline 3 & СЧ-20 & & 0,05 & 25,8 & ПГС \\
\hline 4 & СЧ-30 & & 0,06 & 22,7 & XTC \\
\hline 5 & СЧ-30 & & 0,08 & 34,0 & XTC \\
\hline 6 & СЧ-20 & & 0,1 & 36,1 & ПГС \\
\hline 7 & СЧ-20 & & 0,2 & 58,8 & ПГС \\
\hline
\end{tabular}

центрации 0,01 \% коррозионная стойкость незначительно снизилась (на 6,2 \%) относительно немодифицированного образца.

\section{Выводы}

1. Модифицирование в форме № 1.

1.1. Применение модификатора $M 2$ (концентрация керамической фазы 0,033 \%) при внутриформенном модифицировании серого чугуна способствует увеличению прочности при растяжении на $18,5 \%$, относительной коррозионной стойкости в соляной кислоте - на 13,7 \%, но снижает твердость на 6,6 \% относительно контрольного образца. При концентрации керамической фазы модификатора 0,013 \% увеличиваются и прочность при растяжении (на 17,4 \%), и твердость (на 11,3 \%), относительная коррозионная стойкость - на 7,2 \%.

1.2. При обработке расплава в ковше модификатором $M 2$ (концентрация керамической фазы 0,034 \%) прочность при растяжении увеличилась на $6,7 \%$, твердость на $2,8 \%$; относительная коррозионная стойкость в соляной кислоте увеличилась на $44,1 \%$.

1.3. При обработке металла в ковше модификатором $M 1$ (концентрация активной фазы $0,062 \%$ прочность при растяжении увеличилась незначительно (на 1,1\%), твердость на 9,6 \%, относительная коррозионная стойкость - на 37,6 \%.

1.4. После 3,5 месяцев хранения прочность при растяжении контрольного образца (К1) и образцов, модифицированных в форме, практически не изменилась, а прочность образцов, модифицированных в ковше (концентрации керамических частиц 0,034 и 0,062 \%), увеличилась на 29,4 и 25,3 \% относительно контрольного (К1).

2. Модифицирование в форме № 2 .

2.1. Относительная коррозионная стойкость образцов чугуна в соляной кислоте в пределах концентраций керамической фазы 0,025-0,2 \% увеличилась с 22,7 до 58,8 \%.

3. Полученные результаты свидетельствуют о том, что при исследовании процессов модифицирования серого чугуна (СЧ-18 - СЧ-30) модификаторами, содержащими нанодисперсные керамические фазы (WC, TiC), необходимо учитывать не только концентрации и состав

$$
-199-
$$


модификаторов, но и различные технологические параметры (конструкция, объем литейной формы, способ введения модификаторов и др.).

\section{Список литературы}

[1] Задиранов А.Н., Кац А.М. Теоретические основы кристаллизации металлов и сплавов. М.: Издательство Российского Университета дружбы народов, 2007. 228 с. [Zadiranov A.N., Katz A.M. Theoretical bases of crystallization of metals and alloys, Moskva, Izdatel'stvo Rossijskogo Universiteta druzhby narodov, 2007, 228 p. (in Russian)]

[2] Крушенко Г.Г., Ямских И.С., Бонченков А.А., Мишин А.С. Повышение качества чугунных отливок с помощью нанопорошков. Металлургия машиностроения, 2002, 2 (9), 20-21. [Krushenko G.G., Yamskikh I.S., Bochenkov A., Mishin A.S. Improving the quality of cast iron with the help of Nanopowders, Metallurgy of mechanical engineering, 2002, 2 (9), 20-21 (in Russian)]

[3] Жуков М.Ф., Черский И.Н. Упрочнение металлических, полимерных и эластомерных материалов ультрадисперсными порошками плазмохимического синтеза. Новосибирск: Наука. Сибирская издательская фирма РАН, 1999. 312 c. [Zhukov M.F., Chersky I.N. Hardening of metal, polymer and elastomeric materials by ultrafine powders of plasma chemical synthesis, Novosibirsk, Nauka, Sibirskaya izdatel'skaya firma RAN, 1999. 312 p. (in Russian)]

[4] Сабуров В.П., Черепанов А.Н., Жуков М.Ф. Плазмохимический синтез ультрадисперсных порошков и их применение для модифицирования металлов и сплавов. Новосибирск: Наука. Сибирская издательская фирма РАН, 1995. 344 c. [Saburov V.P., Cherepanov A.N., Zhukov M.F. Plasma chemical synthesis of ultrafine powders and their application for modification of metals and alloys, Novosibirsk, Nauka, Sibirskaya izdatel'skaya firma RAN, 1995. 344 p. (in Russian)]

[5] Хрычиков В.Е., Калинин В.Т., Кривошеев В.А., Доценко Ю.В., Селиверстов В.Ю. Ультрадисперсные модификаторы для повышения качества отливок. Литейное производство, 2007, (7), 2-5. [Khrychikov V.E., Kalinin V.T., Krivosheev V.A., Dotsenko J.V., Seliverstov V.Yu. Ultrafine modifiers to improve the quality of castings, Foundry production, 2007, (7), 2-5 (in Russian)]

[6] Пинкин В.Ф., Каренгин А.Г., Осиненко С.А. Модифицирование высокохромистого чугуна ИСЦ ультрадисперсным порошком. Литейное производство, 1994, (3), 7. [Pinkin V.F., Karengin G.A., Sinenko S.A. Modification of high-chromium cast iron with ultrafine powder, Foundry production, 1994, (3), 7 (in Russian)]

[7] Влас М.И., Калинин В.Т., Хрычиков В.Е., Кривошеев В.А., Меняйло Е.В., Кондрат А.А. Модифицирование износостойких чугунов ультра- и нанодисперсными материалами. $\mathrm{Cu}$ стемные технологии, 2010, 1(66), 150-162. [Vlas, M.I., Kalinin V.T., Hristov E.V., Krivosheev V.A., Menyailo Y.V., Kondrat A.A. Modification of wear-resistant cast iron with ultra- and nanodispersed materials, System technologies, 2010, 1(66), 150-162 (in Russian)]

[8] Полубояров В.А., Коротаева 3.А., Селютин Г.Е., Гаврилов Ю.Ю. Возможности метода механохимических воздействий для приготовления нанодисперсий и модифицирования ими полимеров, металлов, а также для создания керамических материалов. Перспективные материаль, 2009, (3), 351-361. [Poluboyarov V.A., Korotaeva Z.A., Selyutin G.E., Gavrilov Yu.Yu. The possibility of the method of mechanochemical effects for the preparation and modification of nanodispersions of polymers, metals, and for the creation of ceramic materials, Promising materials, 2009, (3), 351-361 (in Russian)] 
[9] Полубояров В.А., Черепанов А.Н., Коротаева З.А., Ушакова Е.П. Способ внепечного модифицирования чугунов и сталей. Пат. 2344180, Российская Федерация, опубл. 20.01.2009. [Poluboyarov V., Cherepanov A., Korotaeva Z.A., Ushakova E.P. Method of modifying cast irons and steels. RF Patent 2344180, publ. 20.01.2009.]

[10] Затуловский С. С. Суспензионная разливка. Киев: Наукова думка, 1981. 260 с. [Zatulovsky S.S. Suspension casting, Kiev, Naukova dumka, 1981. 260 p. (in Russian)]

[11] Лезник И.Д., Беркун А.Ф., Будашева Т.Б., Чебурков Е.М. Способ суспензионной разливки чугунов. Пат. 2142355, Российская Федерация, опубл. 10.12.1999. [Leznik I.D., Berkun A.F., Budaeva T.B., Cheburkov E.M. Method of suspension casting of cast iron. RF Pat. 2142355, publ. 10.12.1999]

[12] Миркин Л.И. Физические основы прочности и пластичности (Введение в теорию дислокаиий). М.: МГУ, 1968. 538 с. [Mirkin L.I. Physical bases of strength and plasticity (introduction to the theory of dislocations), Moskva, MGU, 1968, 538 p. (in Russian)]

[13] Полубояров В.А., Коротаева З.А., Жданок А.А., Кузнецов В.А., Степанова Н.В. Внутриформенное модифицирование чугунов. Исследование влияния модификаторов на основе карбида кремния на процессы кристаллизации серого чугуна. СООБЩЕНИЕ 1. Известия высших учебных заведений. Черная металлургия, 2014, 6, 20-24. [Poluboyarov V.A., Korotaeva Z.A., Zhdanov A.A., Kuznetsov V.A., Stepanova N.V. Intra-mold modification of cast iron. Study of the influence of modifiers based on silicon carbide on the crystallization of grey cast iron. REPORT 1 , News of higher educational institutions, Ferrous metallurgy, 2014, 6, 20-24 (in Russian)]

[14] В. А. Полубояров, 3. А. Коротаева, А. А. Жданок, В. А. Кузнецов, А. В. Самохин. Внутриформенное модифицирование чугунов. Исследование влияния модификаторов, полученных плазмохимическим и СВС методами, на эксплуатационные характеристики серого чугуна. СООБЩЕНИЕ 2. Известия высших учебных заведений. Черная металлургия, 2015, 8, 561-566. [Poluboyarov V.A., Korotaeva Z.A., Zhdanok A.A., Kuznetsov V.A., Samokhin A.V. Intramold modification of cast iron. Investigation of the influence of modifiers produced by plasma chemical and SHS methods on the performance of grey cast iron. REPORT 2, News of higher educational institutions. Ferrous metallurgy, 2015, 8, 561-566 (in Russian)]

[15] Полубояров В.А., Коротаева 3.А., Жданок А.А., Кузнецов В.А., Самохин А.В. Внутриформенное модифицирование чугунов. Влияние состава и концентрации наноразмерных модификаторов на эксплуатационные характеристики серого чугуна. СООБЩЕНИЕ 3. Известия высших учебных заведений. Черная металлургия, 2015, 58 (10), 728-734. [Poluboyarov V.A., Korotaeva Z.A., Zhdanok A.A., Kuznetsov V.A., Samokhin A.V. Intra-mold modification of cast iron. The influence of composition and concentration of nanoscale modifiers on the performance of grey cast iron. REPORT 3, News of Higher Educational Institutions. Ferrous Metallurgy, 2015, 58 (10), 728-734 (in Russian)]

[16] Vladimir A. Poluboyarov, Zoya A. Korotaeva, Alexander A. Zhdanoka and Victor A. Kuznetzov. Nanodisperse Hadfield (110G13L) Steel Modification, Journal of Siberian Federal University. Engineering \&Technologies, 2016, 9(1), 117-125.

[17] Полубояров В.А., Жданок А.А., Коротаева 3.А., Кузнецов В.А. Получение WC и $\mathrm{W}_{2} \mathrm{C}$ из смеси порошков вольфрама, титана и сажи методом самораспространяющегося высокотемпературного синтеза. Неорганические материальl, 2014, 50(5), 508-511. [Poluboyarov V.A.,

$$
-201-
$$


Zhdanok A.A., Korotaeva Z.A., Kuznetsov V.A. Production of $\mathrm{WC}$ and $\mathrm{W}_{2} \mathrm{C}$ from the mixture of tungsten, titanium and soot powders by the method of self-propagating high-temperature synthesis, Inorganic materials, 2014, 50(5), 508-511 (in Russian)] 